\title{
Differences in Responses of Blacks and Whites to American Leaders
}

\author{
Roger D. Masters Dartmouth College, USA
}

\begin{abstract}
How do members of different ethnic or racial groups differ in their responses to the same political events? Previous research has shown that when leaders are seen on television, the viewers' episodic emotional and cognitive responses can influence their attitudes and subsequent voting behavior. In an experimental replication, using excerpts of all candidates in the 1988 American presidential election, episodic emotions elicited by facial displays were again found to produce positive attitude change in white viewers. For blacks, however, the emotions felt while watching leaders-including Jesse Jackson and Michael Dukakis, who elicited highly favorable responses-did not influence posttest attitudes. This contrast between black and white viewers' emotions and attitudes differs from the effects of nonverbal behavior associated with personality or gender. These findings suggest that nonconscious factors may play an important role in the way blacks perceive and react within the American political system.
\end{abstract}

Roger D. Masters is Nelson A. Rockefeller Professor of Government at Dartmouth College. He has over twenty years of research and publication on the relations between the life sciences and human politics. Among many other works in the field of biopolitics, he is author of The Nature of Politics (Yale University Press, 1989) and Beyond Relativism: Science and Human Values (University Press of New England, 1993), as well as coeditor of Ostracism (Elsevier, 1986), Primate Politics (Southern Illinois University Press, 1991), The Sense of Justice: Biological Foundations of Law (Sage, 1992), and The Neurotransmitter Revolution (The Gruter Institute, 1993). Dr. Masters is also editor of the "Biology and Social Life" section of Social Science Information. Correspondence should be addressed to Department of Government, Silsby Hall, Dartmouth College, Hanover, NH 03755, USA.
B ECAUSE THE UBIQUITY of ethnic or racial identification creates the potential for xenophobia and virulent nationalism, it is particularly important to understand the origins of group differences as a factor in human social behavior. Because the dominant perspectives in both Marxist and American social science have paradoxically focused on similar socioeconomic, educational, or cultural variables, differences of ethnicity or race have typically been viewed as traditional or pre-modern "ascriptive" criteria that should not persist (let alone increase in importance) within industrial societies. As a result, few predicted the resurgence of nationalism, racism, "ethnic cleansing," and xenophobia currently observed in societies as diverse as Germany, France, Bosnia, India, or the Ukraine and other formerly communist countries in Eastern Europe.

From an evolutionary perspective, however, these events may be easier to understand (Reynolds, Falger, and Vine, 1987; Shaw and Wong, 1989). Where ecological factors favor a reduction of the scope of social cooperation, individuals are likely to seek phenotypic cues associated with predictable cooperative responses and reciprocity (cf. Frank, 1988); in these circumstances, indicators of "foreign" origin or strangeness are likely to become salient. Such phenomena have been observed among nonhuman primates (Goodall, 1986; de Waal, 1992), and are made possible in contemporary humans because mechanisms of kin recognition have been extended to communities like the modern state (Johnson, 1986, 1987; Johnson, Ratwik, and Sawyer, 1987; Masters, 1993). Thus, we should expect that even in tranquil times ethnicity or race may generate significant differences in emotional and cognitive social behavior.

Research in human ethology and cognitive neuroscience suggests specific theoretical reasons to expect

Acknowledgements. An earlier version of this paper was presented at the 1991 meeting of the American Political Science Association 
that emotional and cognitive reactions toward those of one's own ethnic or linguistic community will differ from those toward "outsiders." According to the "modular view" of the brain now generally accepted in cognitive neuroscience (Gazzaniga, 1988; Dennett, 1992; Fischbach et al., 1992), environmental stimuli are processed by distinct structures in the central nervous system, and "schemata" or established patterns of response are typically represented by ensembles of neuronal response distributed in the brain. Perceptions are not passive reactions to stimulation, but self-organized patterns of distributed response by "neuronal cell assemblies" (Skarda and Freeman, 1990). Ethnic or cultural differences during early development can thus generate differences in perception and emotional response of which the actors are not usually conscious (e.g., Hall, 1959). In this view, xenophobic attitudes may be a rationalization of negative emotional responses which have not been counterbalanced by education, economic interest, and the respect for cultural difference found in stable civilizations.

\section{Information-Processing Modalities}

There are at least five information-processing modalities in which the infant's social experience leads to a "tuning" of innate perceptions and the formation of culturally variable "schemata." All five suggest mechanisms by which unconscious or preconscious information processing and emotional bias might be manifest if not counterbalanced by effective socialization.

\section{Facial Displays}

Neonates perceive and mimic the facial expressions of the mother and other adults. The mother's face is a highly sảlient stimulus for the infant, who finds any termination of smiling gestures aversive-so much so that if a mother or caretaker stops reassuring facial play with the child, the child cries as it does in response to pain (Izard, Hembree, and Huebner, 1987). Furthermore, although human beings have an innate repertoire of facial displays (Ekman and Oster, 1979), cultures differ in the rules for exhibiting them and in their emotional "valence" or meaning (Birdwhistell, 1970; Frey et al., 1993).

Mimicry may be one basis of a lasting differentiation between members of one's own society and foreigners. Experiments have shown that when American adults viewed silent excerpts of unknown politicians from France, Germany, and the United States, they responded with negative emotions and judgments to the foreigners (whereas American politicians elicited neutral responses). When the same viewers saw these excerpts with the sound, so that language identified foreigners, this effect disappeared. The evidence thus indicates that nonverbal behavior can unconsciously elicit negative reactions to outsiders (Warnecke, Masters, and Kempter, 1992).

\section{Rhythm of Movement and Perception}

"Within a few hours of birth, the human neonate adjusts his or her movements to the rhythms of adult speech" (Condor and Sander, 1974). This process has important consequences in shaping the rhythm of speech performance of adults as well as the preferred rhythm of information processing in other modalities and timescales. The way new technologies are used in three similar industrialized societies provides an example. The rhythms in the speech of the television anchors in France, Germany, and the United States differ consistently across individual announcers (Bente, Frey, and Treeck, 1989). The rhythms of silent images of leaders in television newscasts show the same rhythmic patterns (Frey and Bente, 1989).

\section{Phonemic Perception and Utterance}

At birth, the neonate can apparently distinguish the phonemic contrasts used in any known human language. Within hours, the infant prefers to hear the sounds of the surrounding environment. A bilingual mother elicits more positive responses from her newborn when speaking the language of the cultural environment (Mehler, 1986); by six months, phonemic perception has been "tuned" as a function of linguistic experience (Kuhl et al., 1992). As infants mature, they babble at a predictable stage of development, producing a range of utterances that matches cultural patterns. By puberty, the capacity to produce, and even to perceive, foreign speech sounds is greatly reduced, probably because the neuronal links supporting these sensory discriminations have not been reinforced. Sensory deprivation experiments in cats and other animals have shown that such discriminations do indeed need to be reinforced if they are to survive. Among adults, it is extremely difficult to learn to speak a foreign language with the right accent (exceptions, such as the Rassias method, mimic the process of the child's acquisition of the first language).

\section{Body Odor}

Experiments have shown that, at birth, a human infant, like other mammals, can recognize the smell of its mother and distinguish her smell from others. Three facts suggest that this is a deeply important phenomenon. First, one of the artifacts found in almost every early civilization is perfume. Second, on the cognitive level, words associated with disgusting odors are often associated with rejected outsiders: "you smell." Finally, there is a strong preference for familiar odors. Odor may be an 
exceptionally powerful cue for discriminating between insiders and outsiders (cf. Ackerman, 1990; Stoddart, 1990; Kendrick, Lévy, and Keverne, 1992).

\section{Emotional Response}

Stable perceptions, or "schemata," correspond to distributed "neuronal cell assemblies" whose pattern of response often includes distinct sensory modalities (Skarda and Freeman, 1990). Information processing depends on matching perception to memory. Both associative learning and memory are mediated by the hippocampus, amygdala, and other neuroanatomical structures that govern the states we call "emotions" and "moods" (Mishkin and Appenzeller, 1987; ZolaMorgan and Squire, 1990; LeDoux, 1994). As a result of this, episodic emotions or feelings during an event are distinct patterns of autonomic arousal and psychophysiological response which integrate different sensory modalities when establishing or shaping lasting attitudes.

\section{Responses to American Political Leaders}

The responses of viewers to visual images of national leaders can provide a valuable way to explore an evolutionary approach to between-group differences in social behavior. ${ }^{1}$ Cross-cultural studies suffer from the absence of common language and nonverbal display rules. In contrast, when members of diverse ethnic or racial groups in a single country, especially if of comparable age and educational level, see the same known and powerful political leaders, their episodic emotional and cognitive responses are presumably shaped by comparable attitudes and memories. Can sociocultural, racial, or ethnic differences influence perceptions or feelings at a preconscious level, quite apart from conscious or cognitively learned beliefs and attitudes? If so, do such effects arise when comparable black and white viewers observe the same political events within the United States?

When people see leaders on television, their emotions during the experience are elicited not only by nonverbal and verbal cues, but also by their prior memories, attitudes, and beliefs. Moreover, these episodic emotions are far more powerful than cognitive factors in producing attitude change (Sullivan and Masters, 1988; Marcus and MacKuen, 1993). This helps explain not only why politicians run advertisements, but also why people watch debates between presidential candidates. Experimental studies of responses to leaders can therefore make it possible to analyze ethnic differences in patterns of perception, emotional response, and attitude change whose relevance transcends the question of election outcomes.

\section{When people see leaders on television, their emotions during the experience are elicited not only by nonverbal and verbal cues, but also by their prior memories, attitudes, and beliefs}

The emotional responses and attitude changes of viewers watching rival leaders depend on multiple factors (Masters, 1989a). When the same subjects respond to excerpts of leaders of opposed parties, each leader's behavior as well as each viewer's perceptions, emotions, previous attitudes, and cognitive processing can have a significant influence in modifying attitude, with the pattern of these effects varying depending on the individual. Conversely, when the same stimuli are seen by different viewers or in different settings, such variables as personality, gender, and context should have significant effects. Variation associated with personality and gender should not be reducible to socioeconomic background, since each of these three factors is to some degree independent (Eaves, Eysenck, and Martin, 1989).

To assess differences between the responses of whites and blacks to American leaders, it is therefore necessary to examine cultural differences while controlling other sources of individual variability. While facial displays are evocative and meaningful stimuli, their effects are not constant across all situations or for all viewers. In addition to the displays performed and the status of the leader, such factors as the viewer's attitudes, gender, personality, and TV-watching all influence emotional responses and attitude changes (for a review, see Masters and Sullivan, 1993). Ethnic or cultural background should modify the overall pattern in which these nonverbal cues and cognitive information are integrated by viewers. For example, whereas personality apparently impinges primarily on the decoding and description of cues (Clancy, 1992), ethnicity or race should be reflected in the overall pattern of integrating the type of nonverbal cue, emotion, attitude, and other cognitive variables.

The weighting of factors in a multiple regression model of viewer response should therefore differ between black and white viewers (cf. Jones, 1988). To test this hypothesis, however, it is important to analyze the responses of comparable viewers. Hence, while some of our studies have used adult subjects, the present work analyzes a sample of black and white college students whose age, education, and political experience is roughly comparable. Although the present study makes no pretense at ecologically valid sampling, differences between blacks and whites are even greater in the American population as a whole than in this sample matched 
for age and education; as a result, the experimental sample reported here should be, if anything, structured to minimize group differences in response patterns. ${ }^{2}$ As with all experimental research care should be used in extrapolating the findings reported below. In particular, it needs to be emphasized that the study concerns responses of blacks and whites to national leaders in 1988, and provides no information about the responses of either group to local leaders or to other campaigns.

\section{TV, Facial Displays, and Political Leaders}

The way a leader's facial displays shown on television can influence public opinion has been explored in a series of experiments carried out from 1982 through 1989 with colleagues at Dartmouth (for reviews, see Lanzetta et al., 1985; Masters and Sullivan, 1993). ${ }^{3}$ In particular, we have sought to show how episodic events-watching specific sequences of known leaders exhibiting different types of nonverbal cues-can affect the viewers' emotions, impressions of leaders, and potentially lasting attitudes.

These experimental studies have been derived from a combination of ethology, social psychology, and political science. Since ethologists have shown the importance of cues signalling attack, flight, and submission in the social interactions among primates, human facial displays corresponding to these functional categories were the focus of our research. Using criteria derived from ethology and social psychology, excerpts of known leaders that exemplify three types of display-happiness/reassurance, anger/threat, and fear/evasion-were chosen from national TV coverage of press conferences, party rallies, nominating conventions, and speeches (Masters et al., 1986).

In our experiments, subjects were merely told we were interested in the effects of the media on politics (and generally did not suspect our interest was in nonverbal behavior). After answering a standard questionnaire, indicating political opinions and attitudes toward leaders as well as other background information, subjects were presented with videotaped excerpts (20 to 120 seconds in length) showing close-up images of leaders. After each excerpt, viewers typically described the nonverbal behavior of the leader along a number of dimensions (the leader was strong, happy, angry, fearful, etc.), using 0-6 scales to provide measure of perceived display intensity. Then viewers were asked to report on their own emotional feelings during the excerpt, again using 0-6 scales for different emotions (happy, angry, afraid, etc.); these emotional self-reports have been validated by comparing them with viewers' psychophysiological responses. Finally, at the end of most of our studies we measured changes in attitude to see whether the excerpts had changed the viewers' opinions of the leaders.
In some cases, a study used a single leader (President Reagan) exhibiting the three types of display, with systematic variations in the channel of communication (sound-plus-image, image-only, sound-only, filteredsound-plus-image, or text-only); in addition to studies using paper and pencil responses in three or more of these media conditions (Lanzetta et al., 1985; Masters et al., 1986), experimental evidence of psychophysiological effects was used to verify the accuracy of verbal selfreports of emotion (McHugo et al., 1985). In another set of experiments, all candidates during the presidential campaigns of 1984 and 1988 have been shown in two excerpts, one neutral and the other the best happy/reassuring display available early in the campaign year; identical displays were shown to groups of subjects before the first primary election and at the end of the campaign, just before election day (Sullivan and Masters, 1988, 1993b). Another study inserted silent exemplars of Reagan's display behavior in the background of routine TV news stories, so that different groups of subjects saw identical news accompanied by different mixtures of silent facial display cues (Sullivan and Masters, 1993a). Finally, the American studies using the three types of display were replicated in France, using excerpts of three national leaders just before the legislative elections of 1986 (Masters and Sullivan, 1989a, b).

Our findings show that display behavior is potentially of great importance in leader-follower relationships, but that the effects are extremely complex. Viewers accurately describe different types of display: average ratings of excerpts showing happiness/reassurance, anger/threat, fear/evasion or neutral cues consistently show significant differences, with the scales congruent to the type of display rated higher than other descriptive categories (Masters et al., 1986; Masters and Mouchon, 1986). When rivals are shown during a single experiment, particularly at election time, descriptions are correlated with the viewer's established political attitudes, but even then objectively defined differences in nonverbal behavior are clearly perceived by the average citizen (Masters and Sullivan, 1989a, b; Flohr, Tönnesmann, and Pöhls, 1986).

Broadly speaking, happiness/reassurance elicits positive feelings, whereas fear/evasion is most likely to produce negative feelings in viewers. Patterns of response to anger/threat are intermediate: while there was no significant difference between the positive feelings during happiness/reassurance and anger/threat in our French study, Americans felt similarly when watching anger/threat and fear/evasion, each of which elicits less positive and more negative feeling than happy/reassuring excerpts (Sullivan and Masters, 1993a, b; Masters and Sullivan, 1989a, b).

These episodic emotional responses while watching each excerpt do, however, depend very much on the viewers' prior attitudes. As a rule, viewers who support 
a leader are more influenced by the differences in a leader's display behavior, whereas critical viewers are less likely to respond very differently to display cues. Happy/reassurance displays have somewhat different effects for supporters (for whom these excerpts elicit strong positive emotion) and for critics (whose negative feelings are neutralized by these displays). Fear/evasion elicits negative feelings from supporters and critics alike, whereas the patterns of response to anger/threat are more complex, depending on attitude, nationality, and even media condition (Lanzetta et al., 1985; Masters et al. 1986; Sullivan and Masters, 1993a, b; Masters and Sullivan, 1989a, b, 1993).

The emotions felt during exposure to TV scenes of leaders were shown to have potentially lasting effects on viewers' attitudes. Particularly at the outset of a national election campaign, the mere exposure to excerpts of rivals-especially those who were little known-can have significant effects on viewers' ratings of a leader on a 0 to 100 ("thermometer") scale known to correlate with voting behavior (Sullivan and Masters, 1988, 1993b). In the study using displays that were inserted in TV news stories, attitude effects were measured 24 hours after the last exposure: for some viewers (males with neutral pretest attitudes), differences in nonverbal cues significantly influenced posttest attitude, showing that the display effects can last long enough to be further reinforced and become part of durable judgments and feelings (Sullivan and Masters, 1993a).

A number of additional factors also enter into the system by which nonverbal cues communicate feelings and potentially modify attitudes. Among these variables are

- channel of communication (Masters et al., 1986; Masters and Sullivan, 1993);

- performance style of the leader (Sullivan and Masters, 1988, 1993b; Masters and Sullivan, 1989a, b, 1993);

- intensity of display (Masters, 1990: Figure 2; Masters and Sullivan, 1993);

- viewer's pretest attitude to the leader, party, ideology, and other opinions (Sullivan and Masters, 1988, 1993a, b; Masters and Sullivan, 1989a, b);

- viewer's gender (Masters, 1989b; Masters and Carlotti, 1994);

- personality or sensitivity of the viewer (Carlotti, 1988; Clancy, 1992);

- cognitive information (Newton et al., 1987);

- culture (Masters and Mouchon, 1986; Masters and Sullivan, 1989a, b);

- socioeconomic status and ethnic background of viewer (Sullivan and Masters, 1993b);

- status of leader (Masters and Sullivan, 1993; Masters and Carlotti, 1994);

- competitive versus noncompetitive contexts
(McHugo, Lanzetta, and Bush, 1991; Masters and Sullivan, 1993); and

- framing or cueing by news commentator (Newton et al., 1987).

\section{Methods}

During the 1988 American presidential campaign, we replicated the experimental design used to study the effect of happy/reassuring facial displays during the 1984 election (see Sullivan and Masters, 1988). For 1988, a selection of videotape excerpts of all candidates was combined with neutral and happy/reassuring displays of Reagan and Hart used in the 1984 study; at the outset of the 1988 campaign (in February, before the New Hampshire primary), these stimuli were shown to subjects at Dartmouth College, who were asked to describe the display behavior in each excerpt, record their emotional response as they watched it, and then indicate attitudes to all candidates, which could be compared to those prior to the viewing experience (Carlotti, 1988).

In early November, just before the 1988 election, the same stimuli were shown to students from four different universities, providing a more ethnically diverse sample of comparable age and education than has hitherto been possible in our experimental series. ${ }^{4}$ Viewers' responses on pretest items, excerpt-by-excerpt descriptive ratings of strength, happiness, anger, and fear (on 0-6 scales), self-reports of emotional feelings of comfort, happiness, anger, and fear during the excerpt (on similar scales), and posttest attitudes (on the 0 to 100 thermometer scale) were recorded. Data thus not only extend earlier findings to a broad cross-section of subjects reacting to the candidates in the 1988 campaign, but also measure individual and ethnic differences in responses to the same excerpts of Reagan and Hart that had been seen by two samples in 1984.

Since viewers' attitudes and episodic emotions will influence cognition in different ways-depending on the particular events eliciting a response-the predicted difference between blacks and whites can be tested by a multiple regression model like that previously reported for responses to our 1984 study (Sullivan and Masters, 1988: Table 3). Although some have wondered whether multicollinearity produces instability in such models, the results are confirmed by stepwise regression and analysis of variance with viewer's perceptions, emotions, or posttest attitudes as the dependent variable (Masters, 1994). Under these circumstances, multiple regression presents results in a way that allows the most direct comparison of how an array of cognitive and emotional variables are integrated by different kinds of viewers.

Posttest attitude toward each leader was predicted from the following set of independent variables: pretest attitude toward the leader, emotions felt during that 
Table 1. Pretest Attitudes and Emotional Responses to Nonverbal Behavior as Factors Influencing Posttest Attitudes (November, 1988)

\begin{tabular}{|c|c|c|c|c|c|c|c|c|c|}
\hline & \multicolumn{5}{|c|}{ Net Warmth to: } & \multirow[b]{2}{*}{ Ideology } & \multirow[b]{2}{*}{$\begin{array}{l}\text { Assessed } \\
\text { Leadership }\end{array}$} & \multirow[b]{2}{*}{$\begin{array}{c}\text { Issue } \\
\text { Agreement }\end{array}$} & \multirow[b]{2}{*}{ Adjusted $R^{2}$} \\
\hline & $\mathbf{N}$ & $\begin{array}{l}\text { Pretest } \\
\text { Attitude }\end{array}$ & H/R Display & $\begin{array}{l}\text { Neutral } \\
\text { Display }\end{array}$ & $\begin{array}{l}\text { Party Identi- } \\
\text { fication }\end{array}$ & & & & \\
\hline \multicolumn{10}{|l|}{ Bush } \\
\hline Blacks & 47 & 56 & .89 & .71 & -1.00 & .30 & 1.36 & 2.44 & .63 \\
\hline Whites & 151 &.$\underline{55}$ & .65 & .32 & .25 & -.64 & .80 & 2.45 & .78 \\
\hline \multicolumn{10}{|l|}{ Dukakis } \\
\hline Blacks & 48 &.$\underline{55}$ & -.02 & .50 & -2.93 & -3.24 & -0.18 & 1.93 & .47 \\
\hline Whites & 152 & 42 & 1.28 & .12 & -.47 & .69 & .93 & $\underline{2.48}$ & .74 \\
\hline \multicolumn{10}{|l|}{ Dole } \\
\hline Blacks & 49 & .43 & .91 & $1.26^{\star}$ & .42 & 2.19 & 4.70 & -1.36 & .46 \\
\hline $\begin{array}{l}\text { Whites } \\
\text { Jackson }\end{array}$ & 151 & .53 & 1.28 & .39 & 1.51 & .33 & .10 & 1.20 & .42 \\
\hline Blacks & 50 & .52 & .54 & .16 & .87 & -1.11 & $1.53^{\star}$ & 4.51 &.$\underline{58}$ \\
\hline Whites & 151 & 35 & .30 & 1.58 & $-1.49^{\star}$ & -.11 & 2.15 & 2.04 & .76 \\
\hline \multicolumn{10}{|c|}{ Robertson ${ }^{\dagger}$} \\
\hline Whites & 147 & 41 & 85 & $.50^{\star}$ & .71 & .48 & 1.31 & 1.21 & .45 \\
\hline \multicolumn{10}{|l|}{ Reagan $^{\dagger}$} \\
\hline Whites & 152 &.$\underline{63}$ & -.06 & .90 & .98 & .95 & 1.56 & $1.62^{\star}$ & .81 \\
\hline \multicolumn{10}{|l|}{ Hart } \\
\hline Blacks & 49 & $.25^{\star}$ & -.11 & .70 & $-3.06^{\star}$ & 3.53 & 5.70 & 1.61 & .50 \\
\hline Whites & 150 & .35 & 1.10 & 1.41 & .78 & 3.16 & .80 & 4.09 & .51 \\
\hline
\end{tabular}

Studies in 1984 with Identical Excerpts (Predominantly White Samples)

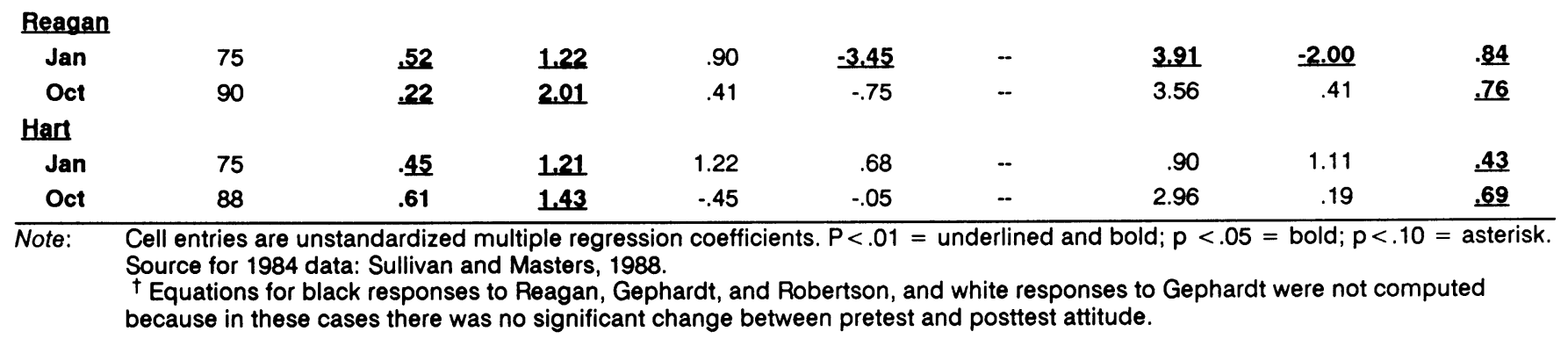

leader's happy/reassurance excerpt, emotions during his neutral excerpt, viewer's party identification, ideology, assessment of the candidate's leadership ability, and issue agreement. This analysis thus permits a comparison of the emotional and cognitive factors that are activated by the experience of watching a significant and known leader on television.

\section{Responses of Black and White Viewers}

In November 1988, white viewers again responded differently to each candidate, showing the importance of individual leaders' popularity and performance styles (see Table 1). While the episodic emotional response to a videotape excerpt of a leader has often been significantly associated with short-term attitude change (Sullivan and Masters, 1988), once again for some leaders it is the happy/reassuring display and for others merely the sight of a leader's neutral behavior that has this effect. Similarly, such attitudinal factors as party identification, issue agreement, or assessed leadership ability differ in salience from one candidate to another.

The study revealed the effect of a decline in popularity or status on the effectiveness of display behavior: the same happy/reassuring excerpts of Reagan and Hart that had been shown to samples of viewers in 1984 were less effective four years later in eliciting positive emotion and more positive attitude. Emotions felt during Reagan's happy excerpt were no longer associated with positive attitude change in 1988-and the pattern of attitude variables activated by the experience was different for each of the samples contrasted in Table 1. Comparing responses after seeing Hart in the two election years, 


\section{It is hard to deny that American blacks and whites live in somewhat distinct subcultures: does this difference influence the way nonverbal displays affect emotions and attitudes after seeing political leaders on television?}

perhaps because of the decline in his political fortunes, pretest attitude had a somewhat weaker association with attitude change in our 1988 study (especially for black viewers); moreover, variables which had no significant effects in 1984-episodic emotions during the neutral excerpt and issue agreement for white viewers, and assessed leadership for black viewers-now contributed significantly to attitude change.

The responses of blacks differ systematically from those of whites-in earlier studies as well as in November 1988. Unlike our previous cross-cultural work (Masters and Sullivan, 1989a, b), this comparison cannot be confounded by differences in the nonverbal display repertoire itself: all subjects saw the same excerpts of the same national leaders. Nor can linguistic differenceswhether in the experimental questionnaire or the behavior of leaders-be at issue. It is hard to deny that American blacks and whites live in somewhat distinct subcultures: does this difference influence the way nonverbal displays affect emotions and attitudes after seeing political leaders on television?

For whites, in 1988 as in 1984, emotions felt during the videotaped excerpts were usually significant factors contributing to posttest attitudes: for most leadersHart, Bush, Dukakis, Dole, and Robertson-emotion to the happy/reassurance excerpt significantly influenced attitudes at $p<.05$ (and all but Bush, at $p<.01$ ); for Reagan, Hart, and Jackson, emotion during the neutral excerpt was significantly associated with posttest attitude at $\mathrm{p}<.01$ (and for Robertson, at $\mathrm{p}<.10$ ). The pattern of factors that influence white viewers depends both on the leader's performance style, as measured by differences in the effectiveness of the evocative excerpt of rival candidates, and social context, as evidenced by the shift in effectiveness of the same excerpts of Reagan and Hart between 1984 and 1988.

Whereas white viewers' emotions during one of the two excerpts significantly increased posttest attitude, the regression equations for blacks do not show this effect $($ at $p<.05)$ for any candidate toward whom the viewing experience induced significant attitude change. And, as if to confirm the lack of responsiveness to the experience of seeing leaders on television, posttest attitudes toward
Reagan, Gephardt, and Robertson were not significantly changed for black subjects. ${ }^{5}$ As in our previous study in France (Masters and Sullivan, 1989a, b), culture seems to shape the way the nonverbal cues of leaders influence the voter.

These findings cannot be understood without noting three important differences between the way blacks and whites respond to identical excerpts of American political leaders. First, for the blacks in our sample the experience of seeing national leaders-including Jackson and Dukakis-did not usually elicit emotional responses which themselves influenced attitude, as has usually been the case for whites in experiments in both 1984 and 1988 (see Table 1). In this experiment, leaders' nonverbal displays, which have consistently been important factors in previous studies in both the United States and France, did not arouse emotions or elicit cognitive responses for blacks.

Second, it is the overall pattern of response, and not a single variable, that is influenced by sociocultural differences like those between American blacks and whites. Where cognition is influenced by a leader's appearance, the specific attributes of relevance differ according the viewers' cultural background (cf. Masters and Sullivan, 1989a, b; Warnecke, Masters, and Kempter, 1992). Hence, for example, Dole's leadership ability was associated with attitude change for blacks, but not for whites. Simplistic assessments of main effects are not likely to capture the subtlety of ethnic or racial differences in perception and response (Jones, 1988).

Finally, these differences are not due to a failure of blacks to perceive display differences between the neutral and the happy/reassuring excerpts. ${ }^{6}$ The differences between the descriptive rating of each leader's neutral and happy/reassuring displays were generally as great for blacks and whites, though mean descriptive scores for both displays were sometimes lower for blacks than for whites (Reagan, Hart, Bush, Gephardt) and sometimes higher (Dukakis, Jackson). The effects can be understood as a more cognitively mediated response pattern among blacks-that is, black viewers generally did not experience the expressive behavior of the American leaders as emotionally arousing even when, as with Dukakis and Jackson, their emotional responses to the excerpts were more positive than those of whites. ${ }^{7}$

\section{Discussion}

Because all subjects were college students, such factors as age, education, and political experience-which sometimes influence responses to leaders-were controlled by our experiment. ${ }^{8}$ Although the perceptions and emotional responses of black and white subjects were similar, these reactions did not impinge on the 


\begin{tabular}{|c|c|c|c|c|}
\hline \multirow{2}{*}{ Independent Variable } & \multicolumn{2}{|c|}{ Positive Emotion } & \multicolumn{2}{|c|}{ Negative Emotion } \\
\hline & Std. Coeff. & Prob. & Std. Coeff. & Prob. \\
\hline \multicolumn{5}{|l|}{ Cognitive Variables } \\
\hline TVNews (Watch) & .10 & .48 & .01 & .94 \\
\hline Vote Probability & -.04 & .80 & -.02 & .88 \\
\hline Liberalism & .17 & .13 & -.17 & .15 \\
\hline Party ID & .01 & .97 & .03 & .85 \\
\hline Newspaper Read & .03 & .83 & .08 & .55 \\
\hline Interest in Campaign & -.13 & .41 & -.16 & .36 \\
\hline \multicolumn{5}{|l|}{ Personality Dimensions } \\
\hline Reward Dependence (x2) & .26 & .05 & .02 & .78 \\
\hline $\begin{array}{l}\text { Harm Avoidance (x2) } \\
\text { (log NS*HA2/RD) }\end{array}$ &. .02 & .91 & -.18 & .21 \\
\hline \multicolumn{5}{|l|}{ Description of Displays } \\
\hline $\begin{array}{l}\text { Total Positive Description } \\
\text { (Strong + Happy) }\end{array}$ & .30 & .01 & .03 & .83 \\
\hline $\begin{array}{l}\text { Total Negative Description } \\
\text { (Angry + Afraid) }\end{array}$ & $\underline{58}$ & .0001 & .72 & .0001 \\
\hline \multicolumn{5}{|l|}{ Gender } \\
\hline Gender & .15 & .22 & .30 & .02 \\
\hline r-squared & .65 & .001 & .78 & .0004 \\
\hline $\begin{array}{l}\text { Source of data }=\text { se } \\
\text { Table presents stan } \\
p<.10=\text { asterisk. } \\
\text { scores, but no indep } \\
\text { significant, } p=.57 \text { ) } \\
\text { consistent with the } \\
\text { features (Masters, }\end{array}$ & $\begin{array}{l}\text { irsonality dim } \\
\text { ficients and } \\
\text { model was } \\
\text { ble was signi } \\
\text { equation pre } \\
\text { at effects of }\end{array}$ & $\begin{array}{l}\text { sed on } 0 \\
: p<.0 \\
\text { ith same } \\
\text { e equati } \\
\text { tive eme } \\
\text { ire largel }\end{array}$ & $\begin{array}{l}\text { ty Inventory } \\
\mathrm{p}<.05=\mathrm{b} \\
x c e p t \text { for om } \\
\text { otion, the r-s } \\
\text { jain not sign } \\
\text { differences i }\end{array}$ & $\begin{array}{l}1986,1987) . \\
\text { scriptive } \\
18 \text { (not } \\
78 \text { ). This is } \\
\text { tion of display }\end{array}$ \\
\hline
\end{tabular}

blacks' attitudes as they did for whites, both in this experiment and in prior studies. A number of possible reasons may account for this result: differences in attitude, different patterns of response to nonverbal cues, or black alienation from the political process (leading to a less emotional and more cognitive response to American political leaders).

\section{Differences in Attitude}

The first and most obvious possibility is that the black subjects in our study differed from whites in their attitudes. While our experimental procedures controlled for some demographic variables, perhaps blacks differ along other dimensions of attitude or political belief.

While possible, this explanation is hardly convincing. Because viewers saw excerpts of eight different national leaders, our data provide eight distinct experimental treatments for the same subjects. Factors such as the frequency of watching TV or reading newspapers, the probability of voting, interest in the campaign, liberalism, or party identification do not have a consistent effect on either positive or negative emotions (e.g., Table 2). Although both race and gender influence pretest attitudes toward each leader, there is no consistent pattern in the direction or intensity of black or white opinions about the candidates (Table 3 ).

For example, that blacks' emotional responses to Jesse Jackson had little effect on posttest attitudes toward him might be explained by their very positive

Table 3. Black and White Subjects' Pretest Attitudes to Candidates (November 1988 Sample, by Gender; Mean Rating, 0-100 Thermometer Scale)

\begin{tabular}{|c|c|c|c|c|}
\hline & \multicolumn{2}{|c|}{ Male } & \multicolumn{2}{|c|}{ Female } \\
\hline & $\begin{array}{c}\text { Black } \\
(21)\end{array}$ & $\begin{array}{c}\text { White } \\
\text { (51) }\end{array}$ & $\begin{array}{c}\text { Black } \\
\text { (25) }\end{array}$ & $\begin{array}{c}\text { White } \\
(75)\end{array}$ \\
\hline Reagan & 47.2 & 60.5 & 35.0 & 55.1 \\
\hline Hart & 45.2 & 47.6 & 50.6 & 44.7 \\
\hline Bush & 42.2 & 52.1 & 37.0 & 48.0 \\
\hline Dukakis & 67.1 & 54.4 & 71.6 & 63.7 \\
\hline Jackson & 83.5 & 52.3 & 87.8 & 49.4 \\
\hline Dole & 39.3 & 59.3 & 47.2 & 52.0 \\
\hline Gephardt & 39.0 & 51.8 & 43.6 & 45.9 \\
\hline Robertson & 30.0 & 33.3 & 36.8 & 40.2 \\
\hline
\end{tabular}


pretest scores (averaging 83.5 for black males and 87.8 for black females): no white leader elicited such positive judgments from white viewers. With such positive ratings at the outset of the experiment, it would be difficult for a single viewing experience to improve responses. It is harder to see how this would account for the absence of attitude change associated with emotions felt while watching the white leaders, toward whom attitudes range as widely as for whites (though blacks were more positive toward Dukakis than were whites toward any candidate).

The cognitive variables customarily used by political scientists are especially weak as an explanation because a different mechanism would be needed to explain the lack of emotional reactions to Reagan and Hartleaders from both parties with highly evocative display behavior who received relatively low ratings among blacks. More likely, judging from the regression model in Table 2, the answer is to be found in the mode of response to nonverbal behavior.

\section{Response to Nonverbal Cues}

As noted above, cognitive neuroscientists have found that differences in early experience shape the way perception and response are integrated in the human brain. Such a process could generate ethnic differences in the way the same events are performed and perceived (Frey et al., 1993). In prior cross-cultural studies, we have found that similar facial displays of anger/threat elicited more positive emotional responses in French viewers than in Americans (Masters and Sullivan, 1989a, b); for samples of Americans, moreover, randomly selected excerpts of foreign leaders consistently elicit more negative responses than those of fellow citizens (Warnecke, Masters, and Kempter, 1992). Even within the United States, regional differences in nonverbal behavior have been noted (Birdwhistell, 1970).

If black nonverbal displays differ from those of whites, viewers in different ethnic groups may have distinct expectations about nonverbal behavior. For example, a smile can be an ingratiating cue of subordination (as in a restaurant waiter or household servant) rather than an indication of self-confidence and reassurance. If the long history of discrimination led American blacks to use public displays of smiling in this submissive manner, our experimental design of showing displays that whites describe as happy/reassuring would have emphasized behavior that blacks associated with non-dominant roles and behaviors.

\section{Black Alienation}

An alternative explanation for the apparent dissociation of emotion from cognition among blacks might be alienation. When a viewer sees foreigners whose behavior is not likely to have any significant effects on meaningful outcomes, reactions are more likely to be cognitively driven; even in responding to American leaders, our subjects' emotional responses are less likely to influence attitudes when watching leaders whose status has declined (e.g., Hart and Reagan in this study [Table 1]; Mondale in 1984 [Sullivan and Masters, 1988]). If blacks are highly alienated from the American political system, they might have perceived all candidates-even those like Dukakis, for whom they had positive attitudes as an individual-as unlikely to have meaningful effects on their lives.

Contrary to racially prejudiced stereotypes, blacks in our study seem to be more cognitive than whites when judging leaders (as measured by the posttest thermometer). Since neuroscientists emphasize that emotional arousal continues to be tightly linked to memory for 12 to 16 weeks after associative learning (ZolaMorgan and Squire, 1990), this would suggest that the black subjects were not using the experience of watching leaders as a means of gaining new information about the candidates. In this explanation, the absence of attitude effects attributable to the emotional responses to any of the candidates could therefore be viewed as an indication that blacks were alienated from the political process itself rather than from individual leaders in the American political system.

\section{Conclusion}

Our experimental design does not permit a choice among the explanations offered above. While further studies are badly needed, this report should be adequate to suggest that the differences between blacks and whites in American politics may extend to the way emotions influence cognition and attitude. This finding could help to explain why individuals from different groups so often experience the same events in such widely divergent ways. In American politics, it would suggest that the gap between blacks and whites may be larger than has been expected, since it transcends questions of income and education, extending to emotional reactions of which people are normally not even aware.

This interpretation would be consistent with Entman's study of images of blacks on local television newscasts (Entman, 1990a, b). While overt racist language has declined, Entman finds important, apparently unconscious selective bias in the images and portrayal of blacks and whites. Similarly, as Jamieson (1992) shows, such campaign devices as the infamous "Willie Horton" $\mathrm{ad}^{9}$ can generate negative attitudes toward a candidate by the subliminal association of unwanted attributes or feared outcomes with an appropriate image. These studies show how cues of which viewers are unconscious can elicit emotions that in turn shape attitudes, and suggest 
that this process may be of particular relevance to the relationships between blacks and whites in the United States. If we are to understand the transformations in politics engendered by television, attention to such nonverbal and emotional factors is essential.

Theoretically, the results have broader implications. The social sciences need to consider the possibility that ethnic tensions can arise from a failure to control processes that are unconscious. Socialization and cultural norms determine who is perceived as a member of "our society," either encouraging diversity or reinforcing hostility to strangers. But it does not follow that all forms of ethnic tension are "caused" by the consciously held doctrines or ideologies that have been developed to justify negative feelings toward outsiders. Such attributions of priority to conscious expressions of racism may confuse cause and effect, ignoring the ecological pressures, social dynamics, and emotional arousal that can lead to the eruption of ethnic conflict. 10

If blacks who have full citizenship in the United States sometimes react differently than whites when responding to leaders during an election campaign, differences in emotion and cognition must be far more pronounced in cases of open hostility between racial, ethnic, or national groups. As the findings reported here might be extended to Bosnian Muslims and Serbs, Francophones and Anglophones in Quebec, Jews and Palestinians in Israel and the West Bank, Catholics and Protestants in Northern Ireland, or Hindus and Muslims in India, they suggest that the maintenance of a legal social order requires continuous effort. Not only democratic institutions, but even a modicum of civilization itself, may be threatened by the tendency of emotional arousal to be dissociated from cognitive information processing when politics is reduced to "us" versus "them."

\section{Notes}

1. Throughout this article, I will use the terms "ethnic or racial" to describe the differences between American blacks and whites. Either term alone could have ideological connotations. On the one hand, "race" is often taken to imply inherited differences associated with skin color and other genetically mediated traits, whereas the behavior at issue arises from sociocultural group differences that develop during early childhood experience. On the other hand, however, to speak of "ethnicity" (as did earlier drafts of the article) can be taken as a challenge to the integration of blacks in American culture. Whatever the word chosen, the group differences studied here seem important not only in the relations of blacks and whites in the United States, but more generally whenever the variables summarized in the first section of the paper influence the complex social identifications operating in heterogeneous or multicultural industrial societies. Nothing in the present study should be interpreted to imply that blacks differ neurologically or cognitively from whites in any way associated with the so-called genetics of "race."

2. The concern for "external validity," often expressed by critics of experimental research based on samples like those reported here, is ironic on three counts. First, many political consultants are successfully using "focus groups" not unlike experimental samples to pretest television ads and campaign themes (e.g., Jamieson, 1992); practical politicians seem less concerned about this methodological question than some academic political scientists.

Second, in the natural sciences, disconfirmation of another scholar's experimental research is a characteristic means of gaining status and prestige; in the social sciences, those who question experimental results sometimes seem to prefer methodological criticism to replication. For example, Science recently published-and the national press discussed at length - a study showing, in a sample of 40 homosexual brothers and other kin, localization of genetic similarity of homosexuals to "Xq28, the subtelomeric region of the long arm of the sex chromosome" (Hamer et al. 1993). Since it is virtually certain that male homosexuality has diverse etiologies, some of which are environmental (Posner, 1992), the interest and importance of this study is not contradicted by considerations of either sample size or external validity; rather, the ongoing process of science requires further research to ascertain whether the reported findings can be replicated and -if soestablishing the limits of the populations and circumstances to which they apply. The same is, one hopes, the case with the present study.

Finally, "external validity" concerns a number of factors, of which sampling is only one; equally if not more important is the relevance of the behavior studied to the phenomenon of interest. Some political scientists who focus on public opinion polling data have questioned experimental findings on the grounds of unrepresentative sampling, without considering the artificial and unrepresentative nature of the task of answering a questionnaire; obviously, the solution is not either representative polls or unrepresentative experimental samples, but rather the extent to which both methods generate congruent results (e.g., Bartels, 1993; Marcus and MacKuen, 1993).

3. My principal colleague in this research program has been Denis $\mathrm{G}$. Sullivan, whose contribution has been essential to my own work in countless ways; as the citations show, our collaboration spans a decade of intensive experimentation and analysis. The most recent experiment in this series, discussed below, was supported by an Interdisciplinary Research Grant to Roger D. Masters (Government) and Gregory J. McHugo (Psychology) from the Rockefeller Center of the Social Sciences, Dartmouth College. Earlier phases of research were supported by grants from the Harry Frank Guggenheim Foundation (to John T. Lanzetta, Roger D. Masters, and Denis G. Sullivan), National Science Foundation (to Denis G. Sullivan, John T. Lanzetta, and Roger D. Masters), Maison des Sciences de l'Homme, Paris (to Roger D. Masters), Spoor Grant for the Study of Leadership, Rockefeller Center for the Social Sciences, Dartmouth College (to Roger D. Masters and Denis G. Sullivan), and the Gruter Institute for Law and Behavioral Research (to Roger D. Masters).

4. Sites for this study, arranged through the kind and energetic assistance of George Miller at Southern Illinois University at Carbondale, were SUNY Potsdam, Boston University, Grambling State University, and Dartmouth College; data from an additional sample at Southern Illinois have not been available for analysis due to technical reasons. I particularly thank Denise Baer, David Bositis, Allan McBride, and George Miller for their invaluable assistance in administering the experiment, and Steven J. Carlotti, Jr., whose stimulus selection and experimental design in the study in February 1988 (Carlotti, 1988) was being replicated. I also thank Gregory J. McHugo, coinvestigator on the Rockefeller Center Grant that funded this study, and Jo Steele, Firdaus Dhabhar, Michael Warnecke, David Clancy, Erik Bliss, Liz Rodgers, and Nathan Lewis for assistance with data entry. Preparation of the data and all analyses of the combined sample were conducted by my colleague Denis G. Sullivan. On the problem of "representative" sampling, see below, note 8 .

5. The apparent lack of effects among blacks needs to be interpreted in the light of the negative level as well as lack of 
significant changes in the thermometer scores toward the three leaders in question: President Reagan (black pretest mean $=39.4$, posttest mean $=40.462$, change not significant; white pretest mean $=58.2$, posttest $=60.4$, change significant, $p<.05$ ); Gephardt (black pretest mean $=41.8$, posttest $=38.9$, change not significant; white pretest mean $=49.0$, posttest $=47.8$, change not significant); and Robertson (black pretest mean $=31.7$, posttest $=32.1$, change not significant; white pretest mean $=34.7$, posttest $=31.2$, change significant at $p=.02$ ). Where there was no significant change between pretest and posttest ratings, the regression models are not presented in Table 1.

6. On the role of culture in shaping the interpretation of a cue rather than its perception, see Gazzaniga, 1988, especially Chapter 2.

7. This interpretation is confirmed by using the neutral excerpt of each leader as a baseline and correlating, for the entire sample, the difference between average descriptions of the happy/reassuring and neutral excerpts of each leader with the difference between the average emotional response to his happy/reassuring and his neutral excerpts. This correlation measures the extent to which the perceived display intensity of the happy/reassuring excerpt elicited positive emotion, controlling for the viewers' prior attitudes and other attributes of the viewers or of each candidate.

Although individual scale scores of description and emotional responses have correlations between .00 and .70, across five prior experiments increased positive description is highly correlated $\left(r^{2}=.809\right)$ with increased feelings of net warmth to the happy/reassuring excerpt (Masters, 1990: Figure 2). While this correlation was similar for white viewers in November 1988 , for the black sample at Grambling State the correlation was substantially weaker $\left(r^{2}=.684\right)$.

8. It is true, of course, that this control through sampling might entail a loss of "external validity" (i.e., an error in the generalization of our study to the population at large). Even the supposedly accurate national samples in many public opinion polls, however, sometimes introduce significant bias in the proportions of blacks and other minorities sampled (Febeo, 1993). As in other areas of science, the most reliable control for considerations of external validity is the replication of findings in the course of repeated scientific inquiry by the community of scholars.

9. During the 1988 American Presidential Campaign, this TV advertisement for George Bush, then the Republican nominee, imputed softness on criminals and responsibility for crime to the Democratic nominee, Michael Dukakis. As Governor of Massachusetts, Dukakis had supported the prison furlough system under which a prisoner named William Horton committed rape and assault. The advertisement used images of Horton (who is black - and did not use the name "Willie") and prisoners going in and out of a turnstile to create a misleading impression, ignoring evidence of the program's results and failing to compare the program to similar practices in other states (including California under the Governorship of Ronald Reagan). For a full description and analysis, see Jamieson, 1992: Ch. 1.

10. It needs to be stressed that the distinction between conscious awareness and preconscious or unconscious information processing is not identical to the difference between cognition and emotion. Many forms of learning and memory which we view as highly cognitive are actually outside of human consciousness (Lewicki, Hill, and Czyzewska, 1992; Pratto, 1994). When such preconscious information processing generates contradictory perceptions or responses, moreover, the process of "rationalization" can be traced to what Gazzaniga has called the "interpreter module" - a nonverbal processing center in the left hemisphere that generates a plausible verbal explanation for apparently contradictory or unexpected perceptions and behaviors (Gazzaniga, 1985).

In contrast to the long tradition of seeking cognitive or ideological roots for violent xenophobia, a careful phenomenological account of the right-wing "skinheads" in Germany suggests the absence of any coherent ideological or cognitive mapping (Kramer, 1993).

\section{References}

Ackerman, D. (1990). The Natural History of the Senses. New York: Vintage.

Bartels, L. (1993). "Messages Received: The Political Impact of Media Exposure." American Political Science Review 87:267-85.

Bente, G., S. Frey, and J. Treeck (1989). "Taktgeber der Informationsverarbeitung." In Medien Psychologie Heft 2, 137-60.

Birdwhistell, R.L. (1970). Kinesics and Context. Philadelphia: University of Pennsylvania Press.

Carlotti, S. (1988). "The Faces of the Presidency: Individual Differences in Responses to Nonverbal Behavior of American Leaders." Senior fellow thesis, Dartmouth College.

Clancy, D. (1992). "Paths Not Taken? Personality and an Evolutionary Approach to Politics." Government Department honors thesis, Dartmouth College.

Cloninger, C.R. (1986). "A Unified Biosocial Theory of Personality and Its Role in the Development of Anxiety States." Psychiatric Developments 3:167-226.

Cloninger, C.R. (1987). "A Systematic Method of Clinical Description and Classification of Personality Variants." Archives General of Psychiatry 44:573-88.

Condor, W.S. and L.W. Sander (1974). Science 183:99.

Dennett, D. (1992). Consciousness Explained. Boston: Little Brown.

Eaves, L.J., H.J. Eysenck, and N.G. Martin (1989). Genes, Culture, and Personality: An Empirical Approach. New York: Academic Press.

Ekman, P. and H. Oster (1979). "Facial Expressions of Emotion." Annual Review of Psychology 30:527-54.

Entman, R. (1990a). "Blacks in the News: Television, Modern Racism and Cultural Change." Department of Communication Studies, Northwestern University.

Entman, R. (1990b). "Modern Racism and the Images of Blacks in Local Television News." Critical Studies in Mass Communication 7:1-14.

Febeo, K. (1993). "Gender Differences in Response to the Anita Hill-Clarence Thomas Hearings: A Test of Carol Gilligan's Theory of Interaction Effects." Government Department honors thesis, Dartmouth College.

Fischbach, G.D. et al. (1992). Mind and Brain. Special issue of Scientific American 267(3):48-159.

Flohr, H., W. Tönnesmann, and U. Pöhls (1986). "Studying Leaderfollower Relationships from an Ethological Perspective." Paper presented at the Fifth International Conference on Human Ethology. Tutzing, West Germany.

Frank, R. (1988). Passions within Reason. New York: Norton.

Frey, S. and G. Bente (1989). "Mikroanalyse Medienvermittelter Informationsprozesse zur Anwendung zeitreihen-basierter Notationsprinzipien auf die Untersuchung von Fernsehnachrichten." Kölner Zeitschrift für Soziologie und Sozialpsychologie, Sonderheft 30-1989, "Massenkommunikation", 515-33.

Frey, S., A. Raveau, G. Kempter, C. Darnaud, and G. Argentin (1993). "Mise en évidence du traitement cognitif et affectif du non-verbal." MSH Informations 70:4-23.

Gazzaniga, M. (1985). The Social Brain. New York: Basic Books.

Gazzaniga, M. (1988). Mind Matters. New York: Norton.

Goodall, J. (1986). The Chimpanzees of Gombe: Patterns of Behavior. Cambridge, MA: Harvard University Press.

Hall, E.T. (1959). The Silent Language. Greenwich, CT: Fawcett.

Hamer, D.H., S. Hu, V.L. Magnuson, N. Hu, and A.M.L. Pattalucci (1993). "A Linkage between DNA Markers on the XChromosome and Male Sexual Orientation." Science 261:321-27.

Izard, C.E., E.A. Hembree, and R.R. Huebner (1987). "Infants' Emotion Expressions to Acute Pain: Developmental Change and Stability of Individual Differences." Developmental Psychology 213:105-13.

Jamieson, K.H. (1992). Dirty Politics: Deception, Distraction, and Democracy. New York: Oxford University Press.

Johnson, G.R. (1986). "Kin Selection, Socialization, and Patriotism: An Integrating Theory." Politics and the Life Sciences 4:127-54.

Johnson, G.R. (1987). "In the Name of the Fatherland: An Analysis of Kin Term Usage in Patriotic Speech and Literature." International Political Science Review 8:165-74.

Johnson, G.R., S.H. Ratwik, and T.J. Sawyer (1987). "The Evocative Significance of Kin Terms in Patriotic Speech." In V. Reynolds, 
V. Falger, and I. Vine (eds.), The Sociobiology of Ethnocentrism: Evolutionary Dimensions of Xenophobia, Discrimination, Racism and Nationalism. London: Croom Helm.

Jones, J.M. (1988). "Racism in Black and White: A Bicultural Model of Reaction and Evolution." In P.A. Katz and D.A. Taylor (eds.), Eliminating Racism. New York: Plenum.

Kendrick, K.M., F. Lévy, and E.B. Keverne (1992). "Changes in the Sensory Processing of Olfactory Signals Induced by Birth in Sheep." Science 256:833-36.

Kramer, J. (1993). "Neo-Nazis: A Chaos in the Head." The New Yorker (June 14):52-70.

Kuhl, P.K., K.A. Williams, F. Lacerda, K.N. Stevens, and B. Lindblom (1992). "Linguistic Experience Alters Phonetic Perception in Infants by 6 Months of Age." Science 258:606-8.

Lanzetta, J.T., D.G. Sullivan, R.D. Masters, and G.J. McHugo (1985). 'Viewers' Emotional and Cognitive Responses to Televised Images of Political Leaders." In S. Kraus and R. Perloff (eds.), Mass Media and Political Thought. Beverly Hills, CA: Sage.

LeDoux, J. (1994). "Emotion, Memory and the Brain." Scientific American 270:50-57.

Lewicki, P., T. Hill, and M. Czyzewska (1992). "Nonconscious Acquisition of Information." American Psychologist 47:796-801.

Marcus, G.E. and M.B. MacKuen (1993). "Anxiety, Enthusiasm, and the Vote: The Emotional Underpinnings of Learning and Involvement during Presidential Campaigns." American Political Science Review 87:672-85.

Masters, R.D. (1989a). The Nature of Politics. New Haven, CT: Yale University Press.

Masters, R.D. (1989b). "Gender and Political Cognition." Politics and the Life Sciences 8:3-39.

Masters, R.D. (1990). "Evolutionary Biology and Political Theory." American Political Science Review 84:195-210.

Masters, R.D. (1991). "Individual and Cultural Differences in Response to Leaders' Nonverbal Displays." Journal of Social Issues $47: 151-65$.

Masters, R.D. (1993). "On the Evolution of Political Communities: The Paradox of Eastern and Western Europe in the 1990s." In M.T. McGuire (ed.), Human Nature and the New Europe. Boulder, CO: Westview.

Masters, R.D. (1994). "Cognitive Neuroscience, Emotion, and Leadership." In James Kuklinski (ed.), Political Psychology in Practice. New York: Cambridge University Press. In preparation.

Masters, R.D. and S.J. Carlotti, Jr. (1994). "Gender Differences in Responses to Political Leaders." In L. Ellis (ed.), Social Stratification and Socioeconomic Inequality. Vol II. Boulder, CO: Praeger.

Masters, R.D. and J. Mouchon (1986). "Les Gestes et la Vie Politique." Le Français dans le Monde 203:85-87. Paris: Hachette.

Masters, R.D. and D.G. Sullivan (1989a). "Facial Displays and Political Leadership in France." Behavioural Processes 19:1-30.

Masters, R.D. and D.G. Sullivan (1989b). "Nonverbal Displays and Political Leadership in France and the United States." Political Behavior 11:121-53.

Masters, R.D. and D.G. Sullivan (1993). "Nonverbal Behavioral and Leadership: Emotion and Cognition in Political Information Processing." In S. lyengar and W.J. McGuire (eds.), Explorations in Political Psychology. Durham, NC: Duke University Press.
Masters, R.D., D.G. Sullivan, J.T. Lanzetta, G.J. McHugo, and B.G. Englis (1986). "The Facial Displays of Leaders: Toward an Ethology of Human Politics." Journal of Social and Biological Structures 9:319-43.

McHugo, G.J., J.T. Lanzetta, and L. Bush (1991). "The Effect of Attitudes on Emotional Reactions to Expressive Displays of Political Leaders." Journal of Nonverbal Behavior 15:19-41.

McHugo, G.J., J.T. Lanzetta, D.G. Sullivan, R.D. Masters, and B.G. Englis (1985). "Emotional Reactions to Expressive Displays of a Political Leader." Journal of Personality and Social Psychology 49:1512-29.

Mehler, J. (1986). "Language Comprehension: The Influence of Age, Modality, and Culture." Paper presented to the 37th annual meeting of the Orton Dyslexia Society. Philadelphia, PA. Inglewood, CA: Audio-Stats Educational Services, tape \#916R-21.

Mishkin, M. and T. Appenzeller (1987). "The Anatomy of Memory." Scientific American 256:80-89.

Newton, J.S., R.D. Masters, G.J. McHugo, and D.G. Sullivan (1987). "Making Up Our Minds: Effects of Network Coverage on Viewer Impressions of Leaders." Polity 20:226-46.

Posner, R. (1992). Sex and Reason. Cambridge, MA: Harvard University Press.

Pratto, F. (1994). "Consciousness and Automatic Evaluation." In P. Niedenthal and S. Kitayam (eds.), The Heart's Eye: Emotional Influences in Perception and Attention. San Diego, CA: Academic Press.

Reynolds, V., V. Falger, and I. Vine (1987). The Sociobiology of Ethnocentrism: Evolutionary Dimensions of Xenophobia, Discrimination, Racism and Nationalism. London: Croom Helm.

Shaw, R.P. and Y. Wong (1989). Genetic Seeds of Warfare: Evolution, Nationalism, and Patriotism. Boston: Unwin Hyman.

Skarda, C.A. and W.J. Freeman (1990). "Chaos and the New Science of the Brain." Concepts in Neuroscience 1:275-85.

Stoddart, T.M. (1990). The Scented Ape: The Biology and Culture of Human Odor. New York: Cambridge University Press.

Sullivan, D.G. and R.D. Masters (1988). "'Happy Warriors': Leaders' Facial Displays, Viewers Emotions, and Political Support." American Journal of Political Science 32:345-68.

Sullivan, D.G. and R.D. Masters (1993a). "Biopolitics, the Media and Leadership: Nonverbal Cues, Emotions and Trait Attributions in the Evaluation of Leaders." In A. Somit and S. Peterson (eds.), Research in Biopolitics. Greenwich, CT: JAl Press. In press.

Sullivan, D.G. and R.D. Masters (1993b). "Nonverbal Behavior, Emotions, and Democratic Leadership." In G. Marcus and J. Sullivan (eds.), Reconsidering the Democratic Public. College Park, PA: Pennsylvania State University Press.

de Waal, F. (1992). "The Chimpanzee's Sense of Social Regularity and Its Relation to the Human Sense of Justice." In R.D. Masters and M. Gruter (eds.), The Sense of Justice. Newbury Park, CA: Sage.

Warnecke, A.M., R.D. Masters, and G. Kempter (1992). "The Roots of Nationalism: Nonverbal Behavior and Xenophobia." Ethology and Sociobiology 13:267-82.

Zola-Morgan, S.M. and L.R. Squire (1990). "The Primate Hippocampal Formation: Evidence for a Time-Limited Role in Memory Storage." Science 250:288-90. 